\title{
Operation Mode Analysis, Parameter Matching and Control Strategy Research for a Novel Range-Extended Electric Vehicle
}

\author{
Jianjun $\mathrm{Hu}^{*}$, Guoqiang Zu, Ming Xie and Jia Chen \\ State Key Laboratory of Mechanical Transmission, Chongqing University, Chongqing, 400044, China
}

\begin{abstract}
In order to improve the dynamic performance and endurance mileage of vehicle, operation mode and parameter matching were analyzed and designed on a novel power transmission scheme of range-extended electric vehicle (R-EEV), and the following control strategy of the engine optimization curve was proposed. The simulation was carried out on the Matlab/Simulink software platform and the results showed that the matching parameters and the control strategy of engine were both reasonable, the dynamic performance improved and the vehicle could be operated efficiently.
\end{abstract}

Keywords: Control strategy, Operation mode, Parameter matching, Range-extended electric vehicle.

\section{INTRODUCTION}

As energy crisis and environmental issues such as pollution and global warming have become increasingly worse, new energy resources for automotive industry are required. As a kind of configuration between the pure electric vehicle and conventional hybrid electric vehicle, REEV [1] equipped with auxiliary power unit (APU) on the basis of the pure electric vehicle can guarantee the vehicle's driving range and battery durability, so that the level of the electric energy alternatives to fossil fuels can be increased.

At present, the research and development institutions have focused their work on integrated development of Range-Extender, the design of the matching parameters, vehicle operation mode and the research of control strategy. QU Xiaodong et al. [2] proposed a control strategy of auxiliary power unit (APU), which consists of a gasoline engine and a permanent magnet synchronous motor (PMSM), and the test results show that the control strategy proposed can meet the performance requirements of rangeextended EV very well. Zhou Su et al. [3] proposed a fixedpoint energy management strategy of the engine and matched the parameters for the core components of the powertrain in a series E-REV, and co-simulation based on AVL-Cruise/Simulink was carried out to verify the reasonableness of the matching parameters. Hao YU et al. [4] proposed a double-point energy management control strategy of the engine and analyzed the simulation of matching parameters with AVL-Cruise software for the EREV. The operation mode of the E-REV was divided into four operation modes: the pure electric operation, the engine's economic area operation, the engine's high load operation and the recovery of braking energy operation. Considering the power distribution in urban cycle and highspeed road, Scott engine plug-in electric vehicle with Advisor software verified the advantages of Wankel engine in plug-in electric vehicle. Gregory L. Plett et al. [6] studied

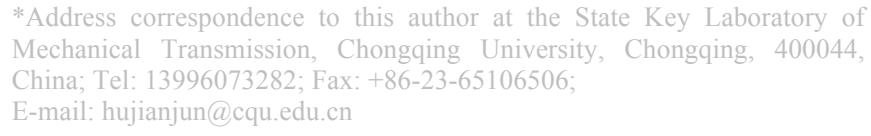

*Address correspondence to this author at the State Key Laboratory of
Mechanical Transmission, Chongqing University, Chongqing, 400044,
China; Tel: 13996073282; Fax: +86-23-65106506; E-mail: hujianjun@cqu.edu.cn

1874-155X/14 the application of boron phosphate batteries on E-REV and conducted a research on the control strategy of the battery energy management. In addition, Matthew Doude, YiminGao et al. [7-9] studied the matching methods of the E-REV and conducted a simulation test by the tool of hardware-in-the-loop (HIL) such as DSPACE.

At present, the series extended range mode is mostly used in the powertrain of the R-EEV at home and abroad, of which energy utilization is very low for the energy conversion of engine power to electric energy and electric energy to motor power. Moreover, compared with four wheel drive, most of the R-EEV is two wheel drive, of which the ground adhesion utilization is so low that the vehicle cannot adapt to some special road condition well and realize the recovery of all-wheel braking energy. Based on the analysis above, a research on a new powertrain of R-EEV was conducted in this study to improve the dynamic performance of vehicle and enhance the adaptability of vehicle to different road conditions.

\section{STRUCTURE AND OPERATION MODE ANALYSIS OF R-EEV}

The structure of R-EEV proposed mainly consists of APU (including engine and integrated starter generator (ISG), which is a PMSM), power driving system (including power battery and driving motor) and transmission system (including wet multi-disc clutch, gearbox, final drive and differential), which are shown in Fig. (1). The main pure electric drive type of the R-EEV is that the driving motor drives the rear axle. The engine drives the ISG motor to transfer the power to battery pack, and the engine can also drive the front axle directly. The R-EEV can work in different modes based on different states.

\subsection{Charge Depleting Mode (CD Mode)}

When the state of charge (SOC) is high ( $\mathrm{SOC}>\mathrm{SOC}_{\text {low }}$ ), the vehicle travels in the EV mode. The engine is turned off when the vehicle runs in $\mathrm{CD}$ mode, which can realize zeroemission. The power flow is shown in Fig. (2). 


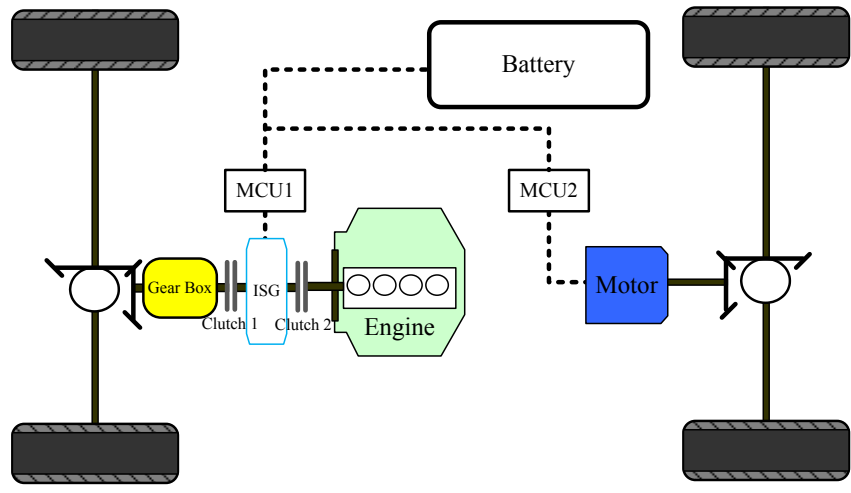

Fig. (1). Structure scheme of R-EEV powertrain.

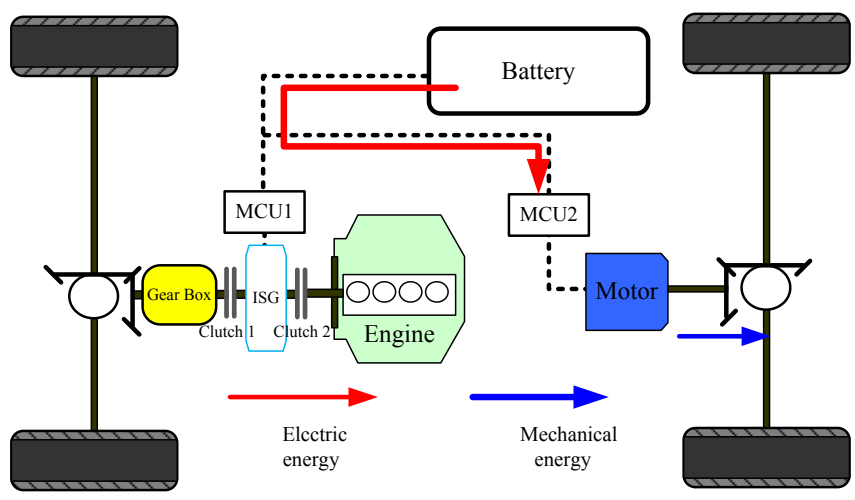

Fig. (2). Power flow in CD mode.

Moreover, when the driving wheel tends to slip on the road of small adhesion coefficient or the demand torque is larger, and the vehicle needs to be started under a large slope. The ISG operates to drive the front axle, while the driving motor goes on driving the rear axle, and the power of both are coupled by the road to realize four-wheel drive (4 WD), so that the adhesive force is fully used and the dynamic performance of vehicle is enhanced. The power flow is shown in Fig. (3).

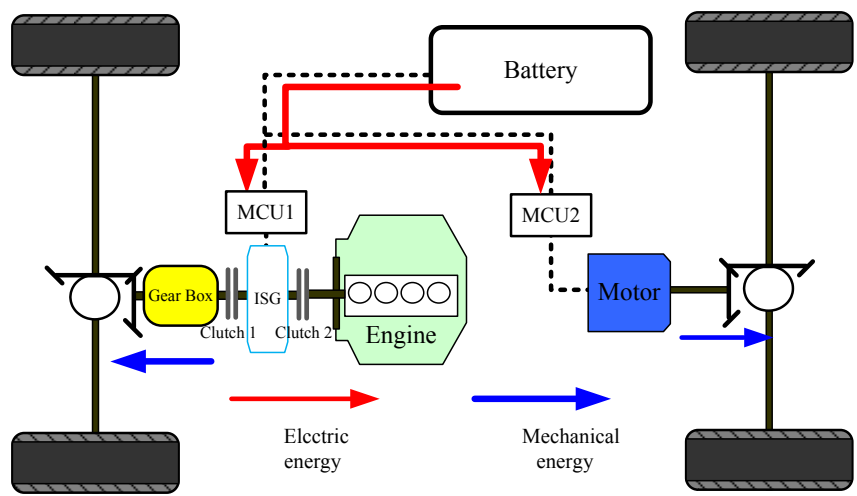

Fig. (3). Power flow in 4 WD mode.

\subsection{Charge Sustaining Mode (CS Mode)}

When the SOC is lower than a limit value $\left(\mathrm{SOC} \leq \mathrm{SOC}_{\text {low }}\right)$, the vehicle runs in the range-extended mode, of which the principle is that each dynamic source works in high efficiency areas and the energy loss owing to the multilevel conversion of energy is reduced as far as possible. The range-extended mode includes series range-extended mode, engine drive mode and co-driving mode.

\subsubsection{Series Range-Extended Mode}

When the velocity is low, the highest velocity is less than $50 \mathrm{~km} / \mathrm{h}$ in the urban driving cycle referring to the ECE cycle, and there is more acceleration and deceleration. At this moment, the demand power is small, and the engine cannot be guaranteed to operate in a high efficiency area when it drives the wheel directly, so the vehicle can be switched to the series drive mode. The power flow is shown in Fig. (4). The engine drives the ISG motor in optimal working site to generate electricity that is directly supplied to the driving motor, which drives the rear axle in the mode, while the extra electricity is stored in the battery pack.

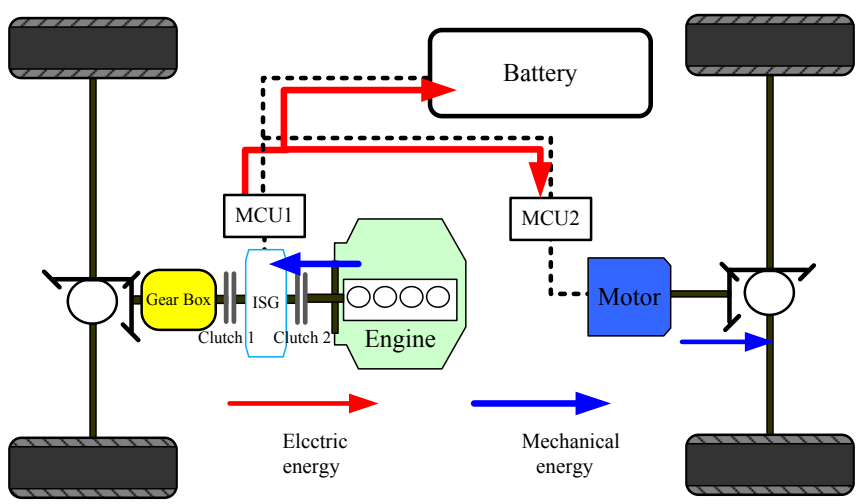

Fig. (4). Power flow in series range-extended mode.

\subsubsection{Engine Drive Mode}

The engine drive mode is used when the vehicle runs at a high cruising speed (the velocity is between 50 and $120 \mathrm{~km} / \mathrm{h}$ referring to the ECE cycle), of which the power flow is shown in Fig. (5). The engine power is directly transferred to the front axle, and the engine operates in a high efficiency area by changing the ISG motor's working state. The power used to drive the vehicle is mainly supplied by the engine of which the extra energy is stored in the battery, and the inadequate power could be supplied by the battery to the ISG motor to meeting the power demand under the acceleration condition of vehicle.

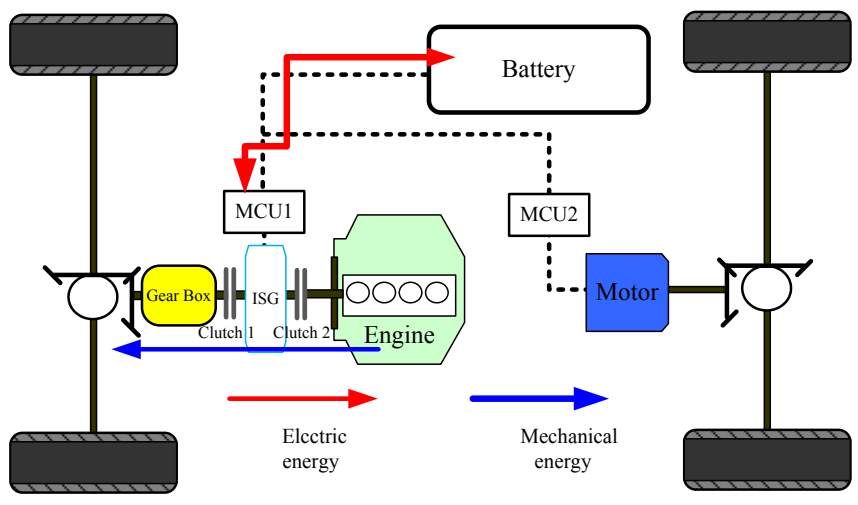

Fig. (5). Power flow in engine drive mode.

\subsubsection{Co-Driving Mode}

The torque demand of vehicle cannot be met by the engine separately when the extra needs to be conducted quickly at a high velocity, while the driving motor can be controlled to drive the rear wheel, and the motor torque is 
coupled with engine torque by the road. The power flow is shown in Fig. (6).

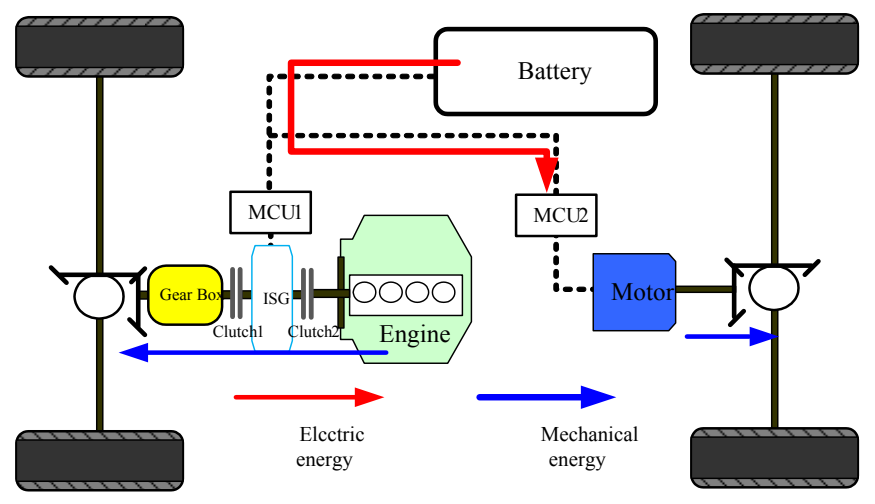

Fig. (6). Power flow in Co-drive mode.

\subsection{Regenerative Brake Mode}

When the vehicle is braking, if the vehicle is operated in EV mode, the ISG and the driving motor are controlled to realize the braking energy recycle by dual shaft braking. If the engine works, the wet multiple disc clutch is disengaged and then the same work as EV mode is carried out. The power flow is shown in Fig. (7).

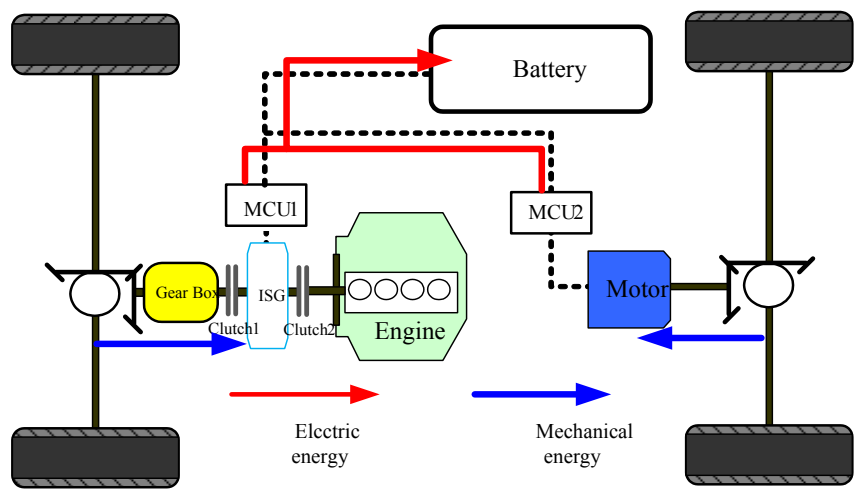

Fig. (7). Power flow in regenerative brake mode.

\section{PARAMETER MATCHING OF POWERTRAIN}

In this study, a traditional vehicle is selected as the prototype and it is refitted. The basic parameters and performance indexes are shown in Tables $\mathbf{1}$ and $\mathbf{2}$.

\subsection{Driving Motor and Rear Axle Final Drive Ratio}

\subsubsection{Determination of Driving Motor Characteristic Parameters}

The corresponding maximum demand power is determined by the performance indexes such as the maximum speed, the maximum grade ability and the acceleration time.

$$
\begin{aligned}
P_{v \max } & =\frac{v_{\text {max }}}{3600 \eta_{T}}\left(m g f+\frac{C_{D} A v_{\max }^{2}}{21.15}\right) \\
P_{i \text { max }} & =\frac{v_{i}\left[\left(m g f \cos \alpha_{\max }+m g \sin \alpha_{\max }+\frac{C_{D} A v_{i}^{2}}{21.15}\right)\right]}{3600 \eta_{T}}
\end{aligned}
$$

$$
\begin{gathered}
P_{j \max 1}=\frac{\frac{\delta m v_{m}^{2}}{3.6 d t}\left[1-\left(\frac{t_{m}-d t}{t_{m}}\right)^{0.58}\right]+m g f v_{m}+\frac{C_{D} A}{21.15} v_{m}{ }^{3}}{3600 \eta_{T}} \\
P_{j \max 2}=\frac{\frac{\delta m}{2 t_{m}}\left(v_{f}^{2}+v_{b}^{2}\right)+\frac{2}{3} m g f v_{f}+\frac{\rho_{a} C_{D} A}{5} v_{f}^{3}}{1000 \eta_{T}}
\end{gathered}
$$

Table 1. Basic Parameters of Vehicle.

\begin{tabular}{|l|c|}
\hline \multicolumn{1}{|c|}{ Parameters } & Value \\
\hline \hline Curb mass $m_{0} / \mathrm{kg}$ & 1600 \\
\hline Efficiency of powertrain $\eta_{t}$ & 0.92 \\
\hline Windward area $A / \mathrm{m}^{2}$ & 2.1 \\
\hline Final drive ratio of front axle & 4.1 \\
\hline Tire radius $r / \mathrm{m}$ & 0.306 \\
\hline Drag coefficient $C_{D}$ & 0.3 \\
\hline Coefficient of rolling resistance $f$ & 0.015 \\
\hline
\end{tabular}

Table 2. Performance Indexes of R-EEV.

\begin{tabular}{|l|c|}
\hline \multicolumn{1}{|c|}{ Performance index } & Value \\
\hline \hline Maximum Speed vmax $(\mathrm{km} / \mathrm{h})$ & $\begin{array}{c}\text { Maximum } \geq 160 \\
\text { Cruise } 80-120\end{array}$ \\
\hline \hline Maximum grade ability $i_{\max }(\%)$ & $\geq 30$ \\
\hline $0-50 \mathrm{~km} / \mathrm{h}$ acceleration time $t_{0}(\mathrm{~s})$ & $\leq 6$ \\
\hline $0-100 \mathrm{~km} / \mathrm{h}$ acceleration time $t(\mathrm{~s})$ & $\leq 13$ \\
\hline Mileage of EV mode $d_{1} / \mathrm{km}$ & $\geq 80$ \\
\hline Total mileage $(d l+d 2) /(\mathrm{km})$ & $\geq 350$ \\
\hline
\end{tabular}

The explanation of variables related is shown in the appendix I, and the following are the same. Considering that the EV mode is the main operation mode of R-EEV in the paper, the driving motor should meet the required performance index. According to the equations above, the peak power of driving motor is finally determined as $75 \mathrm{~kW}$.

The rated power should not be less than the power that is required when the vehicle cruises at maximum speed (120 $\mathrm{km} / \mathrm{h}$ ), so it is calculated by equation (5):

$P_{m e}=\left(m g f+\frac{C_{D} A v^{2}}{21.15}\right) \frac{0.9 \cdot v_{\max }}{3600 \eta_{T}}$

The overload coefficient of motor is defined as the ratio of motor peak power and rated power, which is expressed as $\lambda=P_{m \max } / P_{m e}$ and valued as $2 \sim 3$ generally. Referring to the specification of motor power (GB/T18488.1) combined with the calculation result of equation (5), the rated power of driving motor is determined as $30 \mathrm{~kW}$. 
In conclusion, a driving motor of the Dongfang Electric Company is selected, and its main parameters are shown in Table 3.

Table 3. Parameters of Driving Motor.

\begin{tabular}{|c|c|}
\hline Parameters & Value \\
\hline \hline Peak power $(\mathrm{kW})$ & 75 \\
\hline Rated power $(\mathrm{kW})$ & 30 \\
\hline Peak torque $(\mathrm{N} \cdot \mathrm{m})$ & 200 \\
\hline Rated torque $(\mathrm{N} \cdot \mathrm{m})$ & 93 \\
\hline Maximum speed (rpm) & 12000 \\
\hline Rated speed (rpm) & 3600 \\
\hline
\end{tabular}

\subsubsection{Determination of Final Drive Speed Ratio}

As it is mentioned in paper [10], when the range of speed regulating above the rated speed is large enough ( $\beta=\frac{n_{\max }}{n_{N}} \geq 2.5$ ), the ratio of gearbox can be determined as constant. Considering that the speed of vehicle is less than $50 \mathrm{~km} / \mathrm{h}$ when it runs in urban driving cycle, the high efficient area of driving motor is near the rated speed, and 90 percent of the maximum speed of driving motor should meet the requirement of the maximum vehicle speed. So the ratio of final drive can be calculated by equation (6):

$i_{r}=0.377 \frac{r \cdot n_{N}}{v_{c}}$ as 7.6.

The final drive speed ratio of the rear axle is determined

\subsection{Parameters Matching of Power Battery}

As mentioned above, the requirements of the electric power system for R-EEV is higher. As the main energy source, power battery should not only satisfy the dynamic performance of the R-EEV but can also recycle the braking feedback energy, and meet the design requirements of the EV mode's endurance mileage. According to the recommended value of the EV driving motor rated voltage $(288 \sim 440 \mathrm{~V})$, and referring to the power source voltage specification of the GB/T18488.1, the voltage of power battery is finally determined as $384 \mathrm{~V}$.

\subsubsection{Power Demand}

The maximum discharging power of power battery should guarantee the dynamic performance of the R-EEV.

$P_{b \max } \geq P_{a}+P_{\max } / \eta_{m}$

The corresponding capacity of battery is:

$C_{p} \geq \frac{1000}{k U_{m}}\left(\frac{P_{\max }}{\eta_{m}}+P_{a}\right)$

\subsubsection{Energy Demand}

The energy of power battery should ensure a certain mileage of EV mode. When the vehicle is operated at a constant speed of $v_{a}$, the driving mileage should reach $d_{1}$. So the energy of power battery should meet the following equation.

$E_{b} \geq \frac{m g f+C_{d} A v_{a}^{2} / 21.15}{3600 \times D O D \eta_{t} \eta_{m} \eta_{b}\left(1-\eta_{a}\right)} \times d_{1}$

The corresponding capacity of battery is:

$C_{E} \geq \frac{m g f+C_{d} A V_{a}^{2} / 21.15}{3.6 \times D O D \eta_{t} \eta_{m} \eta_{b}\left(1-\eta_{a}\right) U_{m}} \times d_{1}$

The capacity-maximum discharge rate curve (Fig. 8) is obtained based on the equations above and relevant data.

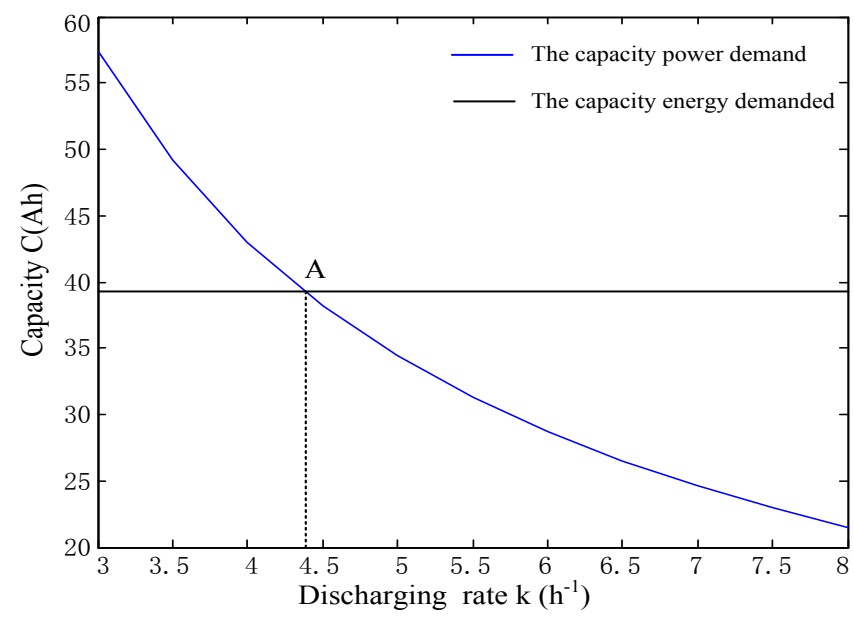

Fig. (8). Relationship between capacity and maximum discharge rate for power battery.

The capacity of the power battery can be determined by the following rule.

$$
C=\min _{k=\min (k)}\left\{\max \left[C_{p}(k), C_{E}(k)\right]\right\}
$$

Table 4. Parameters of Battery.

\begin{tabular}{|c|c|}
\hline Type & Lithium-Iron \\
\hline \hline Cell voltage/V & 3.2 \\
\hline Maximum discharge current & $5 \mathrm{C}$ \\
\hline Maximum charge current & $3 \mathrm{C}$ \\
\hline Rated voltage $/ \mathrm{V}$ & 384 \\
\hline Cell number & 120 \\
\hline SOC range & $0.2 \sim 1$ \\
\hline Capacity /Ah & 40 \\
\hline
\end{tabular}

According to the calculation result, the capacity of power battery is finally determined as $40 \mathrm{Ah}$, the maximum discharge rate is $4.5 \mathrm{~h}^{-1}$, and the energy of battery pack is 15 $\mathrm{kW} \cdot \mathrm{h}$. Table 4 shows the main parameters of lithium-iron power battery selected. 


\subsection{Parameter Design for APU}

APU system mainly includes engine and ISG motor. According to the performance indexes shown in appendix I, the cruising speed in the range-extended mode should reach $80 \mathrm{~km} / \mathrm{h}$. Therefore, the engine power can be obtained by equation (12).

$P_{E}=\frac{v_{a}}{3600 \eta_{t}}\left(m g f+\frac{C_{d} A v_{a}^{2}}{21.15}+m g \lambda\right)$

The engine power calculated by equation (12) is $18 \mathrm{kw}$. Considering that the vehicle should be equipped with a certain amount of reserve power and owe power consumed to some extent, the engine power margin is improved by $10 \%$, and the minimum power of the engine should be 20 $\mathrm{kw}$. Referring to the existing engine specifications, fourcylinder gasoline engine is selected, of which the displacement is $1 \mathrm{~L}$, the maximum power is $40 \mathrm{kw}$ and the maximum torque is $81 \mathrm{N.m}$. The engine universal characteristics are shown in Fig. (9).

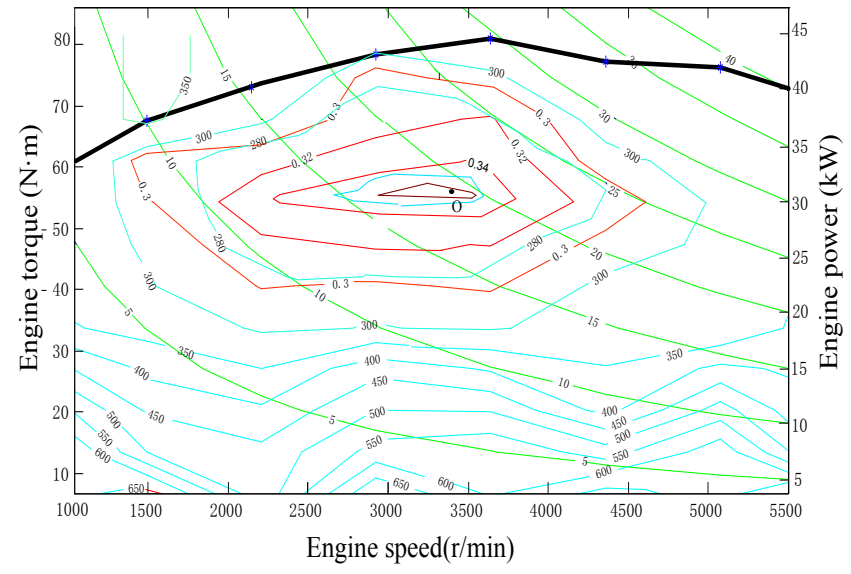

Fig. (9). Engine universal characteristics.

According to the engine universal characteristics, the capacity of fuel tank meeting the driving range $d_{2}$ can be obtained by equation (13).

$V=\frac{P d_{2} b_{e}}{1000 v_{e} \rho}$

The fuel tank capacity calculated by equation (13) is 19.3 L. Finally, the fuel tank capacity is identified as $20 \mathrm{~L}$.

The ISG motor works mainly as a generator used to balance the engine power. The continuous generating region of ISG motor should be coincided with the economic region of engine to the greatest extent for reducing the engine emissions and the fuel consumption. A PMSM is selected as the ISG motor, of which the rated power is $20 \mathrm{~kW} / 3400 \mathrm{rpm}$, the maximum generation power is $40 \mathrm{kw}$ and the maximum speed is $6000 \mathrm{rpm}$.

\subsection{Parameter Matching for Powertrain Transmission}

In cruise mode, the engine should work in a high efficiency area as far as possible. As it is shown in Fig. (9), the maximum speed of engine in a high efficiency area is
$4600 \mathrm{rpm}$ and the minimum speed is $1500 \mathrm{rpm}$. The maximum and minimum speeds of engine should ensure that the vehicle can travel stably at $120 \mathrm{~km} / \mathrm{h}$ and 25 $\mathrm{km} / \mathrm{h}$,respectively. The relationship between velocity and engine speed is the following.

$v=0.377 r n /\left(i \cdot i_{0}\right)$

The maximum and minimum speed ratios of transmission system calculated by equation (14) are 2.6 and 1.05, respectively. In order to ensure engine works in a high efficiency and low emission area, besides meeting the requirements of the vehicle speed, a two-speed factor is selectedas $\mathrm{i}_{\mathrm{g} 1}=2.6, \mathrm{i}_{\mathrm{g} 2}=1.05$, respectively.

\section{ENERGY MANAGEMENT STRATEGY}

Energy management strategy is the core of vehicle control and the key to reduce the engine emissions and fuel consumption of hybrid electric vehicles. In order to improve the power performance and energy utilization of vehicle, logic threshold control strategy is adopted to control R-EEV in this study. The main logic threshold parameters used in the paper are shown in Table 5. According to the operating modes of R-EEV, the control strategies are respectively developed, of which the basic principle is the following: When SOC is high, the vehicle runs in the pure electric drive mode and the driving motor is controlled to work in a high efficiency area. When SOC is low, the vehicle runs in the extended range mode and a conversion of the energy is avoided as far as possible in the battery to reduce the energy loss. The engine is controlled to run in a high efficiency area when it works.

\subsection{Control Strategy for CD Mode}

The control object is mainly the motor during pure electric drive mode. R-EEV is equipped with two motors, which are ISG motor mainly for generation and driving motor mainly for driving. The control method for two motors is similar. Compared to the demand torque determined by the upper level control system with the peak torque under the current motor speed, the motor control system determines whether the motor outputs the demand torque or the peak torque, and then the motor outputs control signals $L_{m}$ and the target torque $T_{m}$. Motor can be used as a generator to recycle part of the brake energy during the brake deceleration of the vehicle for its bi-directional characteristics.

$$
L_{m}=\frac{T_{r}}{T_{m \max }} \text { or } L_{m}^{\prime}=\frac{T_{r}}{T_{\text {max }_{-} g e n}}
$$

\subsection{Control Strategy for CS Mode}

In this phase, the control strategy of power following the engine optimization curve is used. In order to ensure that the engine can operate in a high efficiency and low emission area, the engine optimal working point $\mathrm{O}(56 \mathrm{Nm} / 3400 \mathrm{rpm})$ and high effective working area (within the brown line area where the engine efficiency is greater than 0.3) based on Engine universal characteristics are determined. Besides, the 
Table 5. Logic Threshold Parameters of Energy Management Strategy.

\begin{tabular}{|c|c|c|c|}
\hline Symbol & Parameter Description & Symbol & Parameter Description \\
\hline \hline$T_{r}$ & Demand torque & $T_{e m a x}$ & Maximum torque of engine \\
\hline$T_{\operatorname{mmax}}$ & Maximum torque of motor & $T_{e h}$ & Maximum torque of engine in high efficiency area \\
\hline$S O C_{\min }$ & Minimum value of SOC & $T_{e o p t}$ & Optimal torque of engine in high efficiency area \\
\hline$S O C_{\max }$ & Upper limit value of SOC & $T_{e l}$ & Minimum torque of engine in high efficiency area \\
\hline$S O C_{l o w}$ & Lower limit value of SOC & $v_{\min }$ & Minimum velocity of power generation \\
\hline$S O C_{\text {obj }}$ & Target value of SOC & $v_{o p t}$ & Economic velocity in high efficiency area \\
\hline
\end{tabular}

engine optimal torque curve (the blue dotted line), the maximum torque curve (the pink dotted line) and the minimum torque curve (the red dotted line) in high effective working area are determined. The optimized engine curve is shown in Fig. (10).

\subsubsection{Series Range-Extended Mode}

If the vehicle speed is low and the SOC of the battery has not yet reached its target value $\mathrm{SOC}_{\mathrm{obj}}$, such as it is operated in $\mathrm{F}$ point which is the low efficient working area, the vehicle enters the series range-extended mode. In this case, the engine operates at the optimal point (point $\mathrm{O}$ in Fig. 10), of which the engine fuel efficiency is the highest and the generator's generating power is great. The engine drives the ISG motor to generate electricity in a higher power, which is supplied directly to the driving motor to drive the vehicle, while the rest of the electricity is stored in the power battery.

\subsubsection{Engine Drive Mode}

As mentioned above, the engine's front wheel drive mode is employed when the vehicle travels at a high speed. In this case, the vehicle travels at a stable state, and the requested torque should satisfy the relationship of $\mathrm{T}_{\mathrm{el}} \leq \mathrm{T}_{\mathrm{r}} \leq \mathrm{T}_{\mathrm{emax}}$. The engine outputs the power along different working curves by detecting the value of $T_{r}, T_{e l}, T_{\text {eopt }}, T_{e m a x}$ and the relationship between $\mathrm{SOC}$ and $\mathrm{SOC}_{\min }$.

As it is shown in Fig. (10), when the torque requirement point is $\mathrm{B}$, namely $\mathrm{T}_{\mathrm{r}}>\mathrm{T}_{\mathrm{eh}}$, and if $\mathrm{SOC}>\mathrm{SOC}_{\mathrm{min}}$, then the engine works along the pink dotted line, while the insufficient power is compensated by ISG motor, i.e. $\mathrm{T}_{\mathrm{e}}=\mathrm{T}_{\mathrm{eh}}$ and $\mathrm{T}_{\text {isg }}=\mathrm{T}_{\mathrm{r}}-\mathrm{T}_{\mathrm{e}}$; and if $\mathrm{SOC}<\mathrm{SOC}_{\min }$, then the engine works along the external characteristiccurve, while it drives the ISG motor to generate electricity, and the excrescent energy is stored in the battery, i.e. $\mathrm{T}_{\mathrm{e}}=\mathrm{T}_{\mathrm{emax}}$ and $\mathrm{T}_{\mathrm{isg}}=\mathrm{T}_{\mathrm{e}}-\mathrm{T}_{\mathrm{r}}$. Similarly,

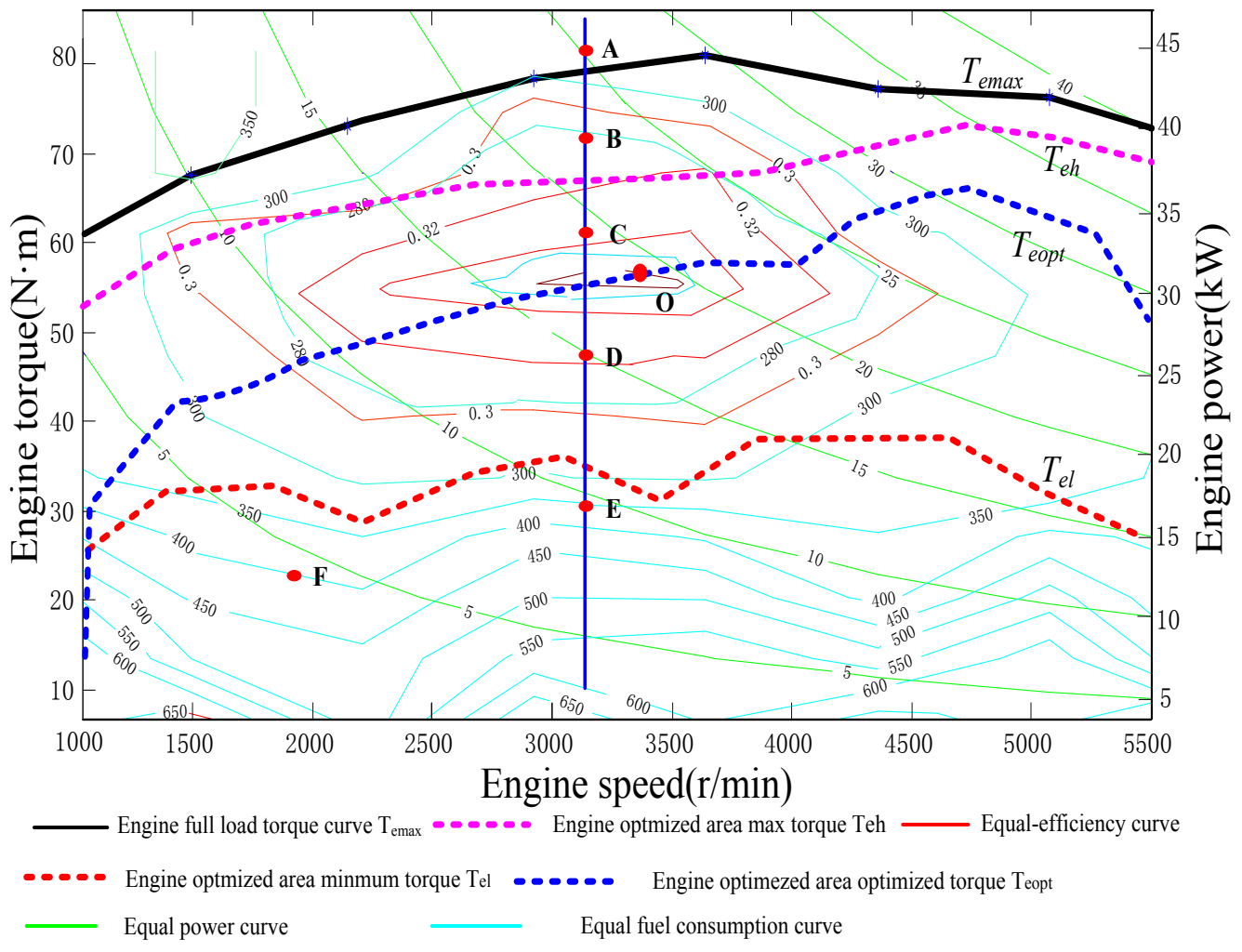

Fig. (10). Optimal curve of engine. 
when the torque requirement point is $\mathrm{C}$, the engine works along the optimal torque curve of the most efficient region, i.e. $\mathrm{T}_{\mathrm{e}}=\mathrm{T}_{\text {eopt }}$ and $\mathrm{T}_{\text {isg }}=\mathrm{T}_{\mathrm{r}}-\mathrm{T}_{\text {eopt }}$ or $\mathrm{T}_{\mathrm{e}}=\mathrm{T}_{\text {eh }}$ and $\mathrm{T}_{\text {isg }}=\mathrm{T}_{\mathrm{e}}-\mathrm{T}_{\mathrm{r}}$; when the torque requirement point is $\mathrm{D}$ or $\mathrm{E}$, the engine works along the blue dotted line and drives ISG motor in a larger torque, i.e. $\mathrm{T}_{\mathrm{e}}=\mathrm{T}_{\text {eopt }}$ and $\mathrm{T}_{\mathrm{isg}}=\mathrm{T}_{\mathrm{e}}-\mathrm{T}_{\mathrm{r}}$, and the SOC quickly returns to the target value, then the vehicle works in pure electric mode.

\subsubsection{Co-Drive Mode}

As mentioned above, if the requested torque is larger than the maximum torque that the engine can supply in the engine drive mode, or the requested torque is larger than the torque that the motor can supply in the pure electric drive mode (point A), then the vehicle enters four wheel drive mode. In this case, the engine power and the motor power are coupled by the ground. Considering that the adjustment of the motor torque is more convenient and the demand torque of the vehicle is larger, the strategy is proposed that the engine works along the external characteristic curve and the insufficient torque is supplied by the motor, i.e. $\mathrm{T}_{\mathrm{e}}=\mathrm{T}_{\mathrm{emax}}$ and $\mathrm{T}_{\mathrm{m}}=\mathrm{T}_{\mathrm{r}}-\mathrm{T}_{\mathrm{e}}$.

\subsection{Control Strategy for regenerative Brake Mode}

The braking mode of hybrid vehicle can be divided into regenerative braking, union braking and mechanical braking according to the different braking intensities. As it is mentioned in the references [11] and [12], the braking is treated as emergency braking when the braking intensity satisfies $z>0.7$. When the braking is not emergency braking and the requested braking intensity satisfies $\mathrm{z}<\mathrm{z}_{\mathrm{gen}}\left(\mathrm{z}_{\mathrm{gen}}\right.$ is the largest regenerative braking intensity that the motor can generate), the whole vehicle braking force can be supplied by the driving motor and ISG. As the braking intensity is increasing, the braking must enter union braking. In the union mode, the drive motor recycles the energy with the most braking power, and the insufficient braking force is supplied by the mechanical braking. In the case of the emergency braking, the mechanical braking should be chosen for the sake of braking security.

\section{SIMULATION}

\subsection{Dynamic Simulation}

The simulation results of the R-EEV on power performance are listed in Table $\mathbf{6}$. The results show that the parameters determined by the R-EEV are reasonable, and the power performance of the R-EEV is better than the prototype vehicle.

\subsection{Economic Simulation}

The endurance mileage of R-EEV contains the endurance mileage of CD mode and CS mode. Simulation condition of CD mode: the initial SOC of the battery is set as 1 ; the vehicle travels at $40 \mathrm{~km} / \mathrm{h}$ and $60 \mathrm{~m} / \mathrm{h}$, respectively. If the $\mathrm{SOC}$ of battery is reduced to the set threshold value $\mathrm{SOC}_{\min }$, the simulation ends. The corresponding endurance mileages are $96.43 \mathrm{~km}$ and $89 \mathrm{~km}$, respectively.

Table 6. Simulation Results of Performance.

\begin{tabular}{|c|c|c|c|}
\hline Parameters & $\begin{array}{c}\text { Prototype } \\
\text { Vehicle }\end{array}$ & $\begin{array}{c}\text { Design } \\
\text { Target }\end{array}$ & $\begin{array}{c}\text { Simulation } \\
\text { Results }\end{array}$ \\
\hline \hline Maximum Velocity & $150 \mathrm{~km} / \mathrm{h}$ & $160 \mathrm{~km} / \mathrm{h}$ & $167 \mathrm{~km} / \mathrm{h}$ \\
\hline Acceleration: $0 \sim 50 \mathrm{~km} / \mathrm{h}$ & - & $6 \mathrm{~s}$ & $5.1 \mathrm{~s}$ \\
\hline Acceleration: $0-100 \mathrm{~km} / \mathrm{h}$ & - & $13 \mathrm{~s}$ & $11.3 \mathrm{~s}$ \\
\hline Grade Climbing: $15 \mathrm{~km} / \mathrm{h}$ & $25 \%$ & $30 \%$ & $45 \%$ \\
\hline
\end{tabular}

In the engine extended-range mode, when the SOC of battery is reduced to 0.4 , the engine starts. According to the requested power of vehicle and the formulated strategy, the engine drives ISG to generate electricity for driving motor and charging of battery. When the battery SOC is up to 0.55 , the engine is turned off and it is switched to the pure electric mode. In the series extended-range mode, this R-EEV is set to travel at $80 \mathrm{~km} / \mathrm{h}$, while the engine runs at or near its optimal operation point. The simulation results show that the total endurance mileage of the R-EEV is up to $373 \mathrm{~km}$, exceeding the expected target.

In addition, the simulation of ECE cycle on endurance mileage of the pure electric mode is carried out. The results are shown in Fig. (11). After one cycle, the battery SOC is reduced from $100 \%$ to $99.27 \%$. According to the equation (16), the endurance mileage of vehicle is calculated as 82.19 $\mathrm{km}$. The result satisfies the performance requirements.
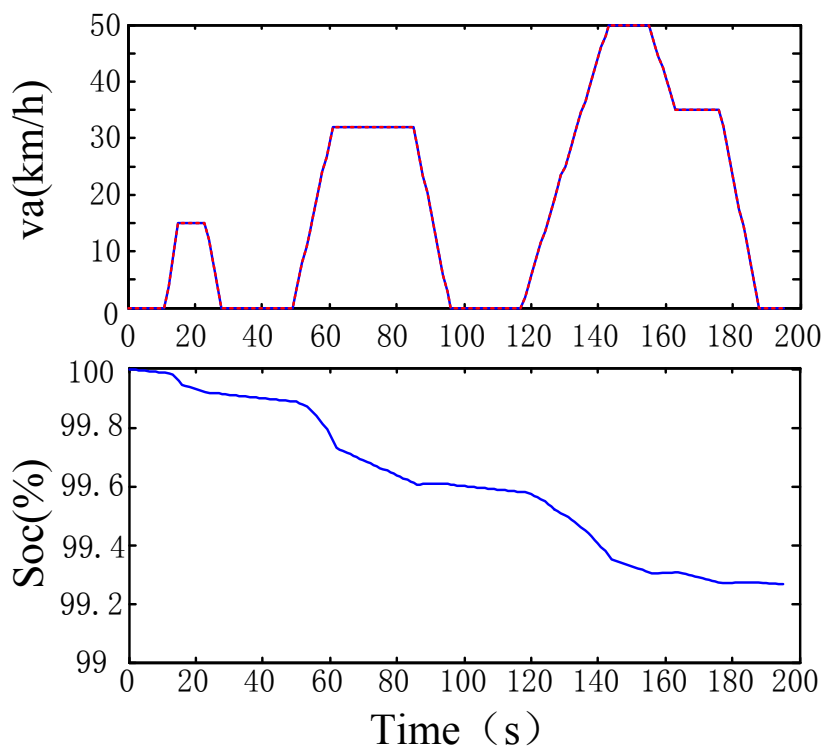

Fig. (11). Simulation results of ECE cycle condition in CD mode.

$S=D O D \cdot S_{c y c} / \triangle S O C$ 

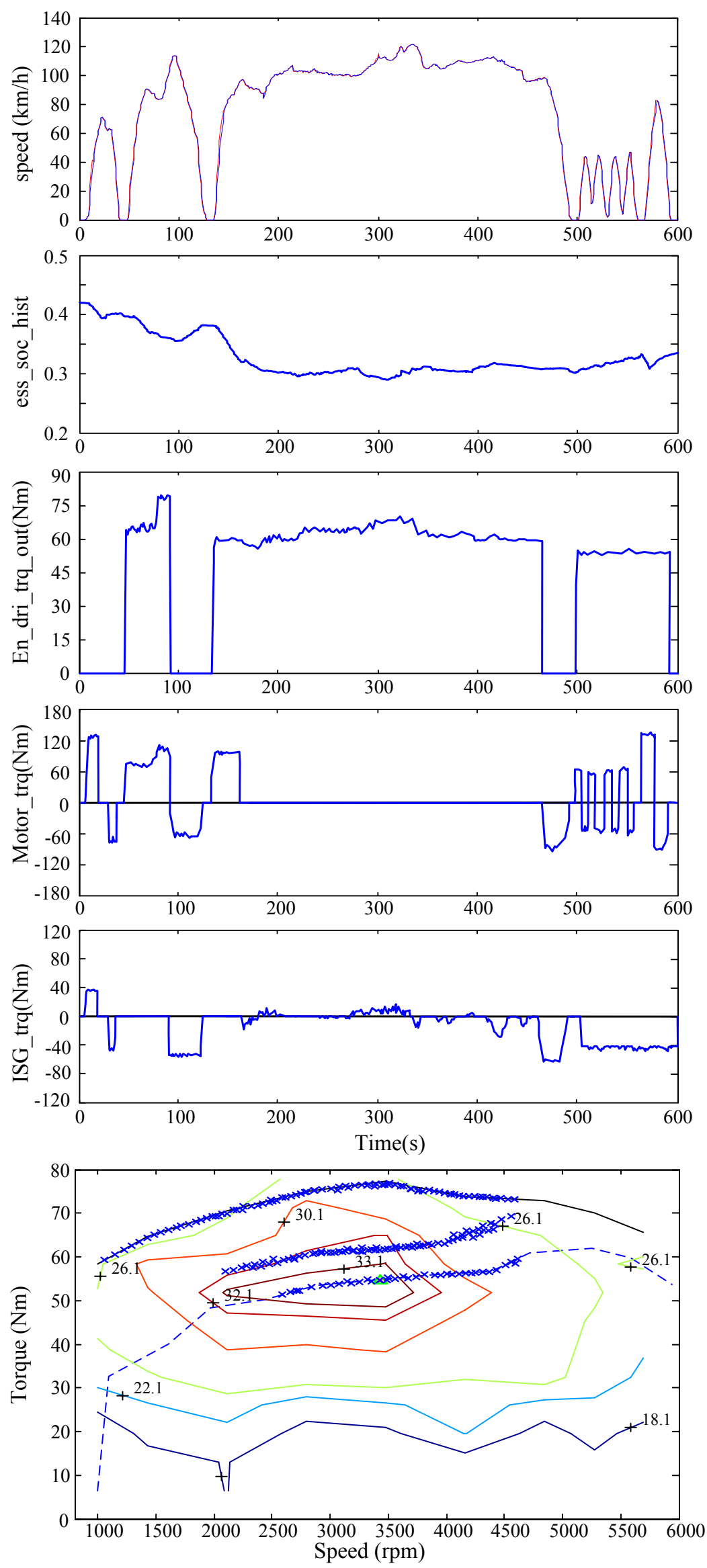

Fig. (12). Simulation results of US06 cycle condition. 

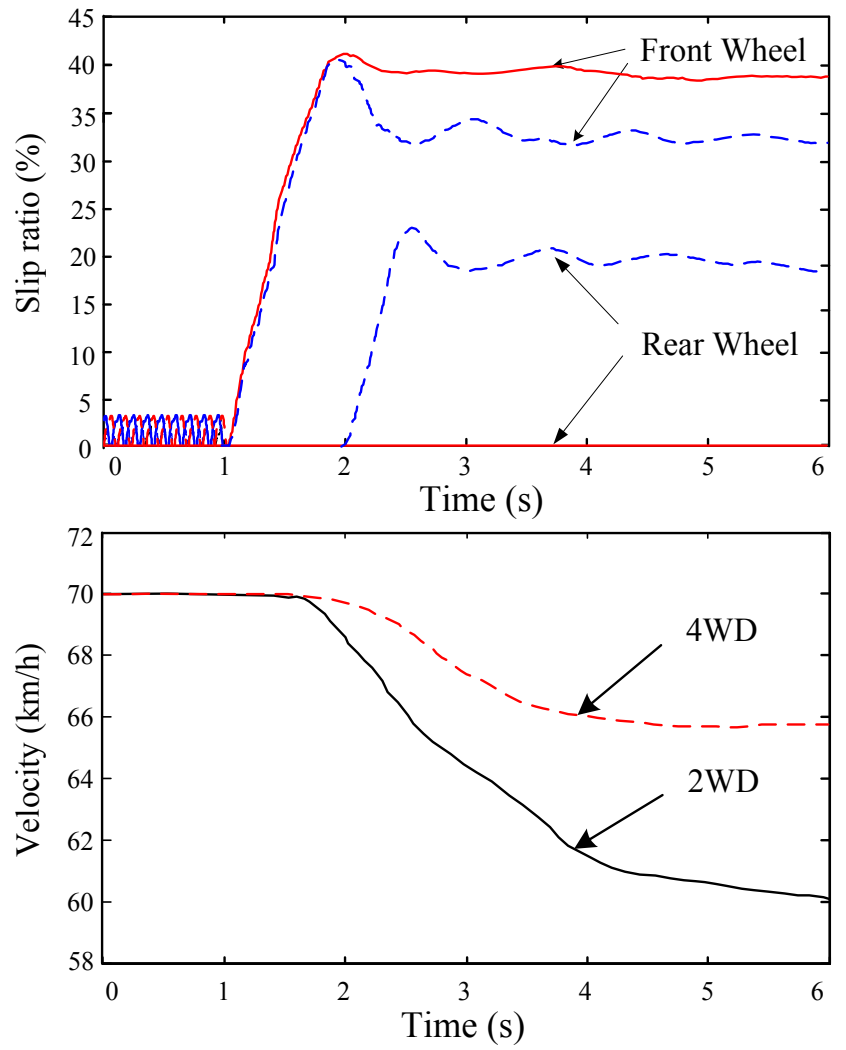

Fig. (13). Performance comparison of two-wheel drive and four-wheel drive.

\subsection{Operation Simulation}

The acceleration and average velocity of US06 driving cycle are higher than other driving cycle. So the simulation of US06 driving cycle is carried out to verify the strategies formulated in this study. In this simulation, the initial SOC of battery is set as 0.43 . Fig. (12) depicts that the initial SOC of battery is higher than the set value 0.4 , and the vehicle finishes the first acceleration process in the pure CD mode by the driving motor and ISG motor. When the battery SOC is decreased to 0.4 , the vehicle switches to extended-range mode. In the second and third acceleration processes of this cycle, the vehicle needs larger drive torque, so the engine and driving motor are both involved in driving the vehicle. When the acceleration is finished, the vehicle operates at high velocity, while it works in engine drive mode. After it runs about 500 seconds, the velocity is basically at $50 \mathrm{~km} / \mathrm{h}$ or lesswhen the SOC is relatively low, so the vehicle switches to the series extended-range mode where the engine is operated in the optimal point, and the vehicle is driven by the rear axle. During the whole cycle, the ISG and drive motor can recycle braking energy to improve the energy utilization ratio of vehicle at real time, while the vehicle can switch to the appropriate operating mode based on the strategy determined to meet the power requirement of vehicle, and the control strategy is reasonable.

Fig. (13) shows the performance comparison of two wheel drive with four wheel drive on the low adhesion coefficient road. The adhesion coefficient of road is set to change from 0.8 to 0.5 in 1 second when the vehicle travels at a constant velocity. As it is shown in Fig. (13), the continuous line represents the curve of wheels slip ratio and vehicle velocity in two-wheel drive mode, and the dotted line represents the curve of wheels slip ratio and the vehicle velocity in four-wheel drive mode. The vehicle travels onto the low adhesion coefficient road after 1 second, while the road adhesion forcedeclines, leading to the slip of driving wheels.

In two-wheel drive mode, the slip ratio of driving wheels rises sharply and exceeds the range of the optimal slip ratio, so the vehicle velocity drops quickly. At the beginning of the second second, the driving motor starts to drive the vehicle together with the engine, and the vehicle switches to co-drive mode to make full use of the road adhesion force, which can reduce the slip rate of the front wheel. At the end of the simulation, the final velocities of two-wheel drive mode and four-wheel drive mode are decreased to $62 \mathrm{~km} / \mathrm{h}$ and 68 $\mathrm{km} / \mathrm{h}$ from $70 \mathrm{~km} / \mathrm{h}$ respectively. The result indicates that the performance is improved.

\section{CONCLUSION}

The operation mode of novel power transmission scheme for range-extended electric vehicle (R-EEV) was analyzed according to the different states of vehicle. Besides, the following control strategy of the engine optimization curve was proposed. Finally, the simulation of vehicle based on the Matlab/Simulink software platform was conducted on the vehicle dynamic performance and the endurance mileage, which verified the reasonability of the matched parameter. The control strategy was verified on the US06 driving cycle and the result indicated that the vehicle in accordance with the vested control strategy can switch to co-drive mode in the rapid acceleration condition, which can better meet the 
power demand; besides, it verifies that the power performance of four-wheel drive is better than two-wheel drive, which is conducted on the transitioning coefficient road.

\section{CONFLICT OF INTEREST}

The authors confirm that this article content has no conflict of interest.

\section{ACKNOWLEDGEMENTS}

This research was supported by the Chongqing Natural Science Foundation (Project NO. CSTC2011BA3019). This project offered all the cost of this series of researches. The authors appreciated the support on these researches.

\section{APPENDIX I}

Symbol Meaning and Valve of parameters in Paper

\begin{tabular}{|c|c|c|c|}
\hline Symbol & Meaning & Unit & Valve \\
\hline $\mathrm{g}$ & Acceleration of gravity & $\mathrm{m} / \mathrm{s}^{2}$ & 9.8 \\
\hline $\mathrm{v}_{\mathrm{i}}$ & Climbing velocity of vehicle & $\mathrm{km} / \mathrm{h}$ & 15 \\
\hline$\alpha_{\max }$ & Maximum climbing angle & $\mathrm{rad}$ & 0.245 \\
\hline$\delta$ & $\begin{array}{c}\text { Equivalent coefficient of revolving } \\
\text { mass changes to linear mass }\end{array}$ & & 1.045 \\
\hline $\mathrm{v}_{\mathrm{b}}$ & $\begin{array}{l}\text { Rotational speed corresponding to } \\
\text { the rated speed of driving motor }\end{array}$ & $\mathrm{m} / \mathrm{s}$ & 13.89 \\
\hline $\mathrm{v}_{\mathrm{f}}$ & Speed of acceleration at end time & $\mathrm{m} / \mathrm{s}$ & 22.22 \\
\hline $\mathrm{i}_{\mathrm{r}}$ & Final drive ratio of rear axle & & \\
\hline$i_{g}$ & Gear box ratio & & \\
\hline $\mathrm{dt}$ & Iteration steps & & 0.1 \\
\hline$\rho_{a}$ & Air density & $\mathrm{N} \cdot \mathrm{s}^{2} \cdot \mathrm{m}^{-4}$ & 1.2258 \\
\hline $\mathrm{P}_{\mathrm{j} \max }$ & $\begin{array}{c}\text { Maximum power corresponding to } \\
\text { Acceleration time }\end{array}$ & $\mathrm{Kw}$ & \\
\hline $\mathrm{P}_{\text {imax }}$ & $\begin{array}{l}\text { Maximum power corresponding to } \\
\text { Maximum climbing grade }\end{array}$ & $\mathrm{Kw}$ & \\
\hline $\mathrm{P}_{\mathrm{vmax}}$ & $\begin{array}{c}\text { Maximum power corresponding to } \\
\text { Maximum speed }\end{array}$ & $\mathrm{Kw}$ & \\
\hline $\mathrm{P}_{\mathrm{a}}$ & $\begin{array}{l}\text { Power consumption of vehicle } \\
\text { accessory }\end{array}$ & $\mathrm{Kw}$ & \\
\hline $\mathrm{k}$ & Maximum discharge rate of battery & $\mathrm{h}^{-1}$ & \\
\hline $\mathrm{C}_{\mathrm{p}}$ & $\begin{array}{c}\text { Capacity of battery determined by } \\
\text { power }\end{array}$ & $A \cdot h$ & \\
\hline $\mathrm{C}_{\mathrm{E}}$ & Capacity of battery determined by & $A \cdot h$ & \\
\hline
\end{tabular}

\begin{tabular}{|c|c|c|c|}
\hline Symbol & Meaning & Unit & Valve \\
\hline \hline DOD & Discharge depth of battery & & \\
\hline$\eta_{\mathrm{t}}$ & Transmission efficiency & & 0.75 \\
\hline$\eta_{\mathrm{m}}$ & $\begin{array}{c}\text { Efficiency of motor and motor } \\
\text { controller }\end{array}$ & & 0.92 \\
\hline$\eta_{\mathrm{b}}$ & $\begin{array}{c}\text { Charge \& discharge efficiency of } \\
\text { battery }\end{array}$ & & 0.95 \\
\hline$\eta_{\mathrm{a}}$ & $\begin{array}{c}\text { Proportional coefficient of energy } \\
\text { consumed by accessory }\end{array}$ & & 0.96 \\
\hline $\mathrm{V}_{\mathrm{a}}$ & Cruising speed in pure electric mode & $\mathrm{km} / \mathrm{h}$ & 50 \\
\hline $\mathrm{V}_{\mathrm{e}}$ & Cruising speed in engine mode & $\mathrm{km} / \mathrm{h}$ & 80 \\
\hline $\mathrm{T}_{\text {max_gen }}$ & $\begin{array}{c}\text { Maximum torque of regenerative } \\
\text { braking }\end{array}$ & $\mathrm{Nm}$ & \\
\hline $\mathrm{n}_{\mathrm{N}}$ & Rated speed of driving motor & $\mathrm{Rpm}$ & 3600 \\
\hline $\mathrm{V}_{\mathrm{c}}$ & $\begin{array}{c}\text { Velocity corresponding to the rated } \\
\text { speed of driving motor }\end{array}$ & $\mathrm{km} / \mathrm{h}$ & 60 \\
\hline $\mathrm{SOC}_{\text {low }}$ & Lower limit valve of SOC \\
\hline mabj
\end{tabular}

\section{REFERENCES}

[1] E.D. Tate, M. Harpster, and P. Savagian, "The electrification of the automobile: from conventional hybrid, to plug-in hybrids, to extended-range electric vehicles," SAE Technical Paper, 2008.

[2] X.D. Qu, Q.N. Wang, and Y.B. Yu, "A study on the control strategy for APU in a extedned-range EV," Automotive Engineering, vol. 35, no. 9, pp. 763-768, 2013.

[3] S. Zhou, J.G. Niu, F. Chen, and F. Pei, "A study on powertrain design and simulation for range-extended electric vehicle," Automotive Engineering, vol. 33, no. 11, pp. 925-927, 2011.

[4] H. Yu, "A study on powertrain simulation of range-extended EV based on cruise software," Electrical Engineering Technology, vol. 39, no. 8, pp. 28-39, 2010.

[5] S. Varnhagen, A. Same, J. Remillard, and J. W. Park, "A numerical investigation on the efficiency of range extending systems using advanced vehicle simulator," Journal of Power Sources, vol. 196, no. 2011, pp. 3360-3370, 2011.

[6] G.L. Plett, "Extended kalman filtering for battery management systems of LiPB-based HEV battery packs Part 2. modeling and identification," Journal of Power Sources, vol. 134, no. 2004, pp. 262-276, 2004.

[7] M. Doude, and G. M. Molen, "Design methodology for a range extended PHEV," Vehicle Power and Propulsion Conference, Dearborn, IEEE Xplore: USA, pp. 817-819, 2009.

[8] Y. Gao and M. Ehsani, "Design and control methodology of plugin hybrid electric vehicles," Vehicle Power and Propulsion Conference, IEEE Xplore: Harbin, China, pp. 1-6, 2009.

[9] E.J. Schacht, B. Bezaire, B.Cooly, K. Bayar, and J.W. Kruckenberg, "Addressing drivability in an extended range electric 
vehicle running an equivalent consumption minimization strategy," SAE Technical Paper, 2011-01-0911, 2011.

[10] J.F. Zhu, and F. Gao, "Matching of motor and powertrain parameters of electric vehicle," Journal of South China University of Technology (Natural Science Edition), vol. 34, no. 3, pp. 33-36, 2006.
[11] M. Wang, Z.C. Sun, etc, "Braking energy recovery system for electric vehicle," Transactions of the Chinese Society for Agricultural Machinery, vol. 43, no. 2, pp. 6-10, 2012.

[12] H.L. Liu, X.P. Dong, and B Zhang, "On regenerative braking control strategy for electric vehicle," Journal of Hefei University of Technology, vol. 35, no. 11, pp. 1484-1487, 2012.

Received: December 8, 2014

(C) Hu et al.; Licensee Bentham Open.

This is an open access article licensed under the terms of the Creative Commons Attribution Non-Commercial License (http://creativecommons.org/licenses/by-nc/4.0/) which permits unrestricted, non-commercial use, distribution and reproduction in any medium, provided the work is properly cited. 